November 2015

\title{
Inflation, Debt, and Default ${ }^{1}$
}

\author{
Sewon Hur
}

University of Pittsburgh

sewonhur@pitt.edu

Illenin Kondo

Federal Reserve Board

illenin@gmail.com

Fabrizio Perri

Federal Reserve Bank of Minneapolis, NBER, and CEPR

fperri@umn.edu

\begin{abstract}
We show that the co-movement of inflation and domestic consumption growth affects both the pricing and the dynamics of nominal domestic debt. In particular a positive co-movement of inflation and consumption makes returns on government bonds negatively correlated with domestic consumption: this lowers risk premia on nominal domestic debt as seen in the data. However, as this co-movement increases, the debt becomes more risky for the government and reduces its incentives to accumulate debt. We find that debt accumulation is overall stronger the higher the co-movement of inflation and consumption. To assess these joint equilibrium properties of debt and interest rates, we calibrate a simple model of domestic default and nominal debt in the presence of exogenous inflation risk and domestic risk averse agents. Consistent with the data, the model also reveals that increased co-movement of inflation and consumption leads to more volatile interest rates.
\end{abstract}

KEYWORDS: inflation, default, domestic debt, interest rates, nominal debt JEL ClASSification CODES: F34, G12

\footnotetext{
${ }^{1}$ The views expressed herein are those of the authors and not necessarily those of the Federal Reserve Bank of Minneapolis, the Federal Reserve Board, or the Federal Reserve System. We thank our discussant Keith Kuester, our outstanding research assistants Alberto Polo and Lucas Husted, and seminar participants at SED in Seoul, University of Pittsburgh, 2013 Fall Midwest Macro Meetings, ECB-CEPR Conference on Heterogeneity in Currency Areas and Macroeconomic Policies, and Federal Reserve Bank of Minneapolis for useful comments.
} 


\section{Introduction}

Currently, in the majority of developed countries, monetary policy and inflation are not determined by the same authorities which set government spending and public debt. Still, the process of inflation and its co-movement with real economic activity can affect the pricing of nominal public debt, public debt dynamics and the possibility of a public default crisis. The goal of this paper is to study how exogenously given changes in the inflation process (driven by, for example, joining a monetary union, or a structural change in the conduct of monetary policy) affect nominal debt pricing and debt dynamics.

To be more concrete, in figure 1 we report quarterly time series for US inflation and consumption growth from 1970 to 2013. The figure shows very clearly how in the first part of the sample (before 1985) the comovement between inflation and consumption growth was strongly negative, while in the second part of the sample (after 1985) it has become slightly positive. If inflation co-varies positively with domestic consumption growth, then returns on domestic nominal debt are high (low) when consumption growth is low (high). This feature makes domestic nominal bonds less risky, from a domestic investor perspective, and thus, if government debt is mostly held domestically, as in many developed countries, they should trade at a, ceteris paribus, lower real interest rate.

The first part of this paper is empirical and it establishes that, for advanced economies, in countries/periods in which the covariance of inflation with domestic consumption growth is high, real interest rates on government bonds tend to be low, suggesting that this covariance is a systematically connected to the pricing of government debt.

In the second part of the paper we develop a simple structural model of debt and default with stochastic inflation that serves two purposes. The first is to show that the empirical connection between debt pricing and inflation process can be understood using simple asset pricing logic. The second is to analyze the impact of change in inflation process on government incentives to issue debt and default.

Our model extends existing models of sovereign debt in two directions. First, we introduce domestic, risk averse, lenders, as opposed to foreign, risk neutral as usually assumed in the literature. This distinction is important since a large amount of public debt is held domestically in advanced economies. Second, we introduce exogenous stochastic inflation so 
Figure 1: Inflation and Consumption Growth in the US

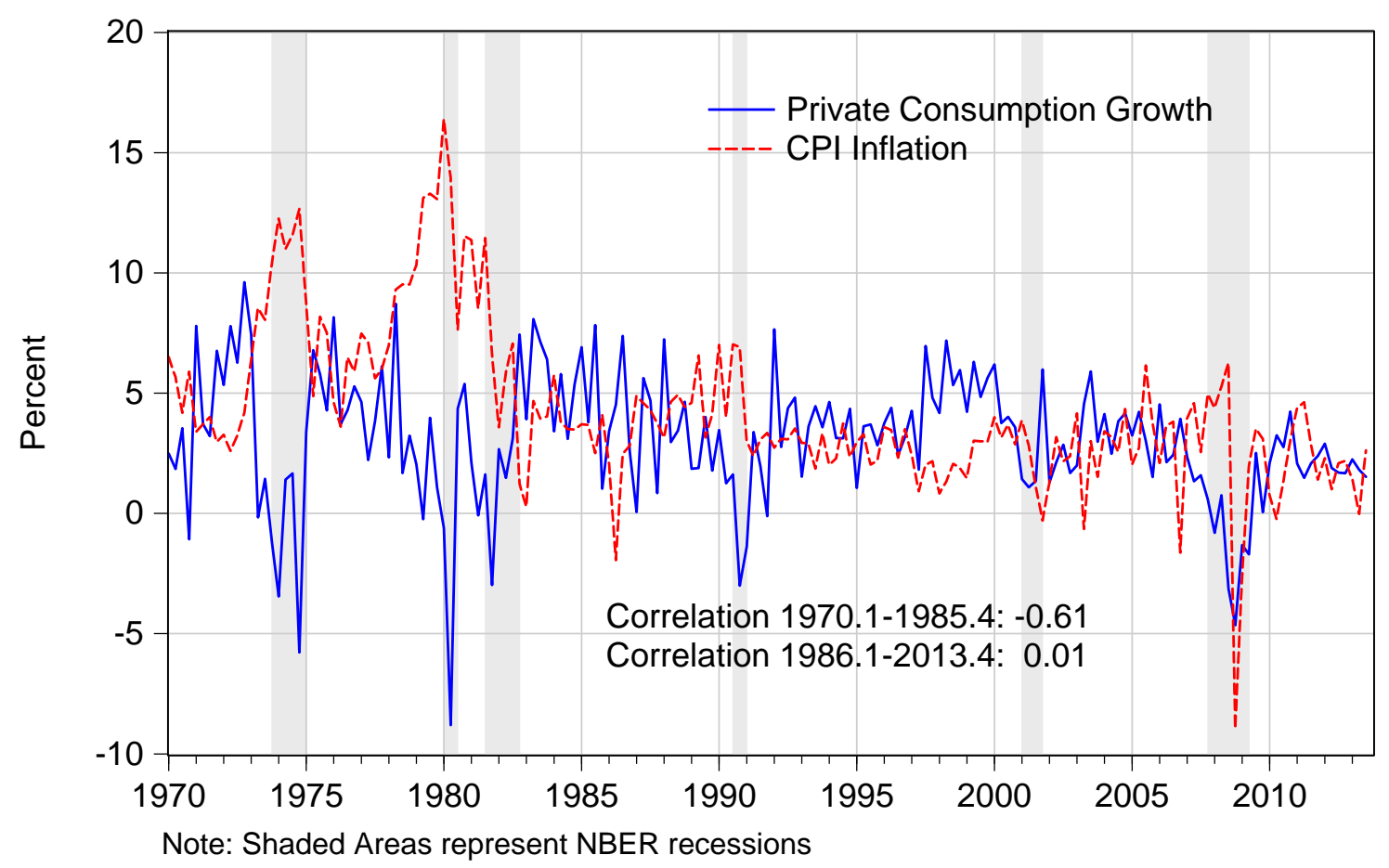

that government bond rates reflect both inflation and default risk. These two features allow us to explicitly analyze the connection between stochastic discount factors of the domestic agents (lenders and borrowers), debt pricing and default probabilities, and to analyze how this relation changes as the co-movement between inflation and consumption growth varies.

Consistent with the data, our model predicts that borrowing costs fall as the covariance of inflation and consumption growth increases. This reflects the reduced risk associated with the nominal debt from the perspective of a domestic lender. Despite the reduced borrowing costs, debt levels do not necessarily rise as the covariance of inflation and consumption growth increases. The key reason for that is that high covariance of inflation and consumption reduces the risk for the lender but increases the risk for the borrower. For a domestic government, debt becomes less attractive the more inflation tends to occur in good times, as real government obligations are larger in states of the world where government values consumption more (i.e. recession). The equilibrium debt dynamics and default will be determined through the interplay of reduced borrowing costs (coming from the lender side) 
and reduced incentives to borrow (coming from the borrower side). Our main findings are [TO BE COMPLETED]

Our paper is related to several strands of literature. On the empirical side our findings are related to studies on the importance of the inflation risk premium and its variation, as, for example, Boudoukh (1993) or Ang et al. (2008). Song (2014) and Campbell et al. (2009) also focus on the covariance of bond returns and other macroeconomic variables such as consumption growth and equity returns. On the theoretical side, the backbone of our set-up is a debt default model with incomplete markets as in Eaton and Gersovitz (1981), Aguiar and Gopinath (2006), or Arellano (2008). While these papers focus on foreign debt, Reinhart and Rogoff (2011) suggest that the connection between default, domestic debt and inflation is an important one. D'Erasmo and Mendoza (2012) and Pouzo and Presno (2014) tackle on the issue of default on domestic debt but do not include inflation. Our general question is also analyzed in recent work that studies how joining a monetary union can affect the probability of a self-fulfilling crisis in a debt default model (see Aguiar et al. 2013 and Corsetti and Dedola 2013). In contrast to those papers, our focus is not on self-fulfilling crises but rather on the impact that inflation can have on fundamentally driven default crises, so we view our work as complementary to theirs. The paper is structured as follows. In section 2 we discuss our empirical findings, section 3 develops a model of domestic debt default, and section 4 presents our main results on the impact of stochastic inflation. Section 5 concludes.

\section{Inflation and Real Interest Rates}

In this section, we study the empirical relation between several conditional moments of inflation and real interest rates on government debt. The main novel finding of the section is that more covariance of inflation with economic activity is robustly and significantly associated with lower interest rates on government debt. Our dataset includes quarterly observations on real consumption (private plus public) growth, inflation, interest rates on government bonds, and government debt-to-GDP ratios for an unbalanced panel of 21 OECD economies from 1960Q1 to 2012Q4. The countries in the dataset are: Australia, Austria, Belgium, Canada, Denmark, Finland, France, Germany, Greece, Italy, Japan, Korea, Mexico, Netherlands, 
Norway, Portugal, Spain, Sweden, Switzerland, United Kingdom, and the United States.

We show that, after controlling for a variety of factors, conditional covariance of inflation and consumption growth is connected to the real rates faced by governments. In particular, high covariance is associated with low real rates, but also increased government debt accumulation. These findings together suggest that the inflation process can have a significant effect on the pricing of domestic debt as well as debt dynamics.

We mainly use quarterly data from the IMF and the OECD to document our empirical findings. We compute inflation as the change in log GDP deflator using data from the OECD. We use nominal interest rates on government bonds from the IMF International Financial Statistics (IFS). For government debt, we use annual OECD data on central government debt relative to GDP and annual series from Reinhart and Rogoff (2011). These annual debt series are linearly interpolated to construct quarterly series. We also use quarterly series from Oxford Economics on gross government debt relative to GDP. Given the different time coverage of these debt series, we combine them to construct our own debt series labeled "HKP". All our results are robust to the use of the underlying debt series alone as shown in the appendix. Quarterly real consumption is constructed as the sum of private and public real consumption using the data from the OECD.

Using this data, we construct real interest rates using expected inflation and the conditional co-movement between inflation and consumption growth. To do, so we follow Boudoukh (1993) and first formulate a vector auto-regression (VAR) model for inflation and consumption growth. The basic VAR is:

$$
\left[\begin{array}{l}
\pi_{i t} \\
g_{i t}
\end{array}\right]=\mathbf{A}_{\mathbf{i}}\left[\begin{array}{l}
\pi_{i t-1} \\
g_{i t-1}
\end{array}\right]+\left[\begin{array}{l}
\varepsilon_{\pi i t} \\
\varepsilon_{g i t}
\end{array}\right]
$$

where $\pi_{i t}$ is inflation, and $g_{i t}$ is the H-P filtered consumption residual in country $i$ in period $t, A_{i}$ is a country-specific 2-by-2 matrix, and $\varepsilon_{\pi i t}$ and $\varepsilon_{g i t}$ are innovations in the two time series. We then estimate the VAR using standard OLS and construct time series for residuals $\varepsilon_{\pi i t}$ and $\varepsilon_{g i t}$ for each country.

We measure the expected inflation as the forward-looking predicted inflation from the VAR, that is $\mathbf{E}\left[\pi_{i, t+1}\right]$. We then derive real rates on the government debt as nominal rates 


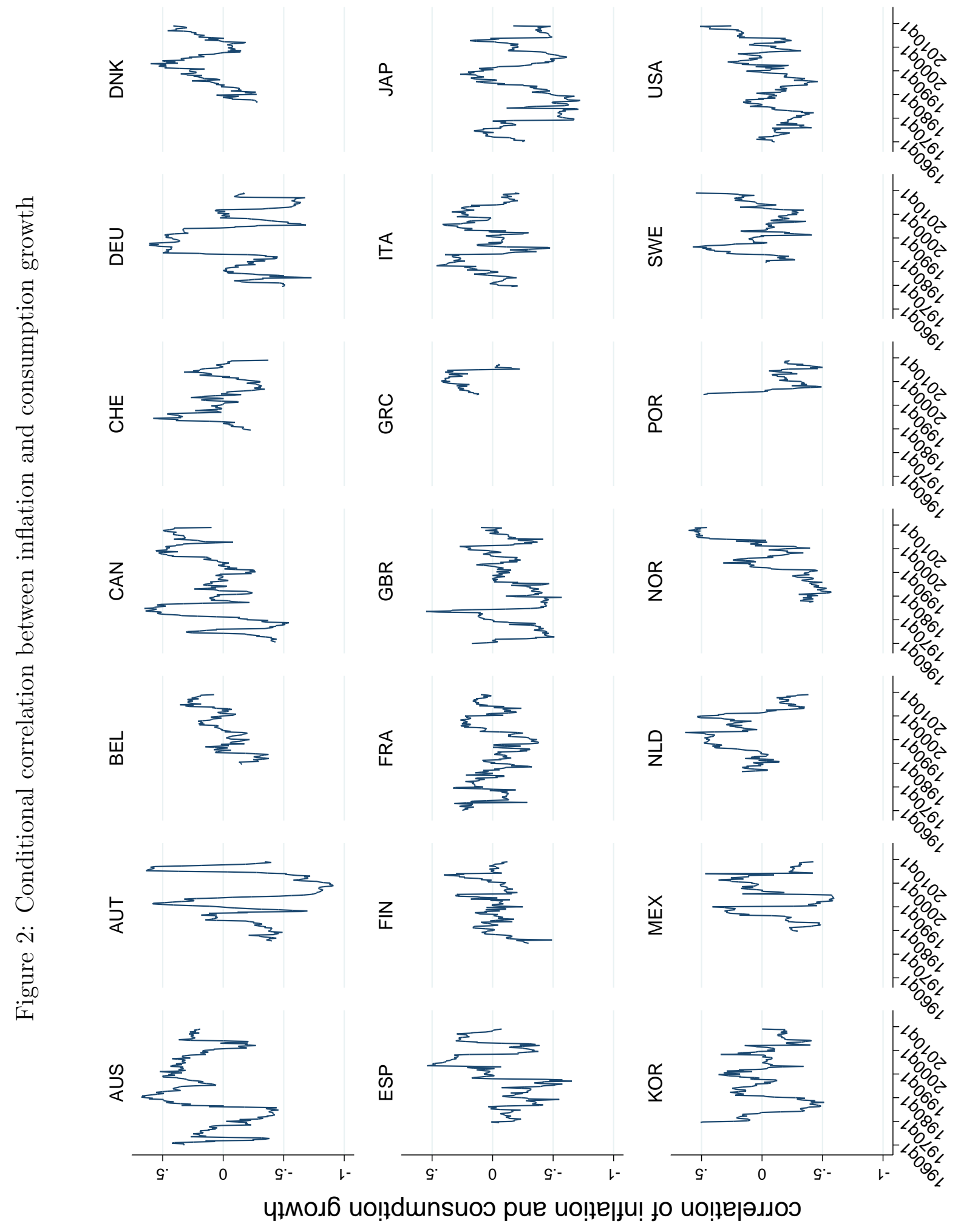


Figure 3: Inflation consumption covariance and real interest rates

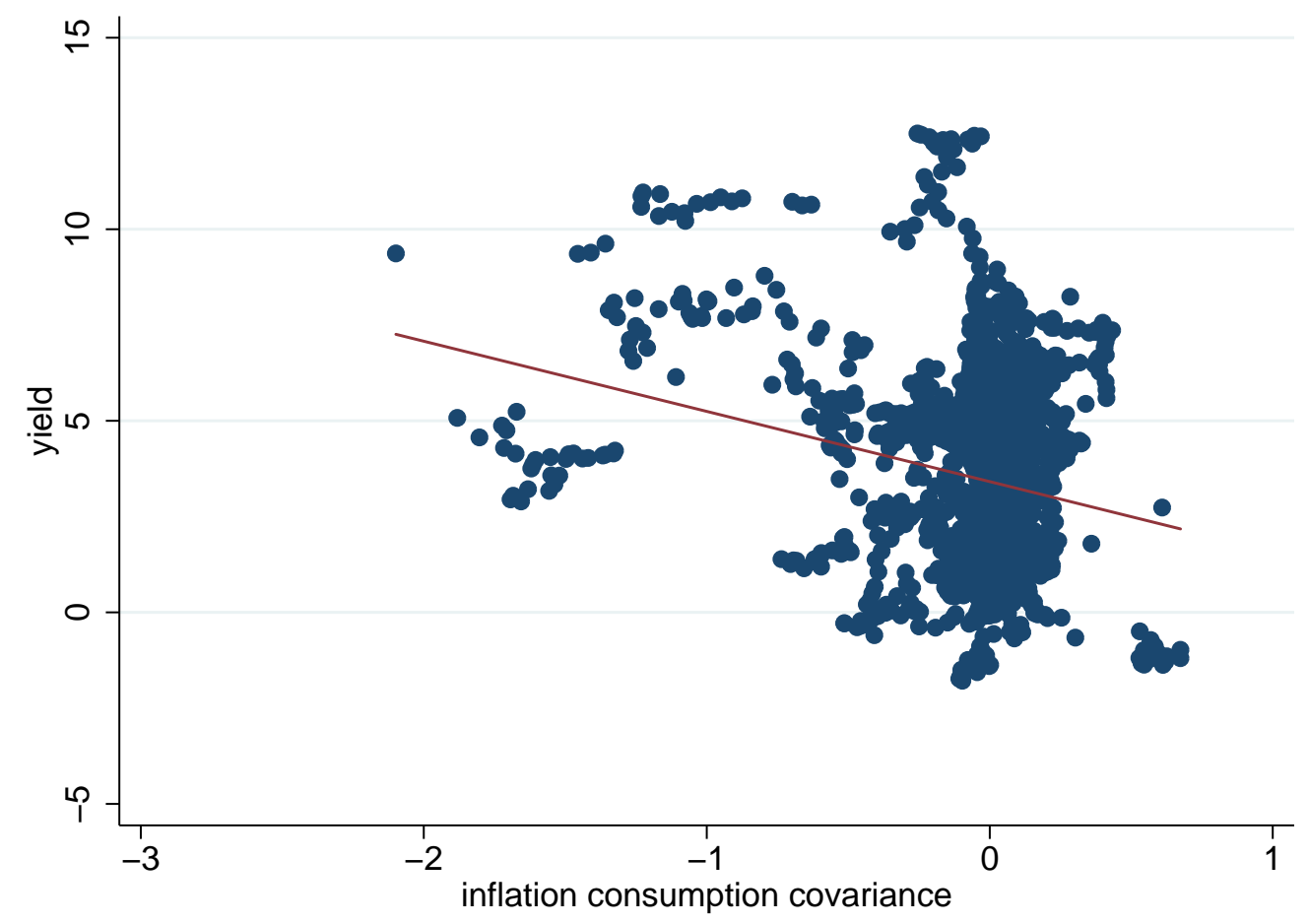

less expected inflation. Finally we measure the conditional co-movement between these two series by measuring the co-variance between the two innovations in overlapping countrywindows, which in our benchmark results are comprised of 28 quarters.

In Figure 2 we plot the path of the conditional correlation for the countries in our sample. Figure 2 illustrates that the co-movement of inflation and consumption growth varies over time and across countries. In many countries such as the U.S., Spain, or Canada the comovement of inflation and consumption growth has clearly increased since the mid-1980s while it has sharply decreased or fluctuated in other countries such as Germany.

With this dataset, we estimate using OLS how the conditional covariance of inflation and consumption growth relates to interest rates faced by governments and the accumulation of government debt. All specifications include a full set of country and time fixed effects.

In Table 1, we regress the real interest rate and debt accumulation on the conditional co-movement of inflation with consumption growth. The key result from Table 1 is that in countries/periods with higher conditional co-movement between inflation and consumption growth, governments face lower interest rates and accumulate more debt. 
Figure 3 and Table 1 show the lower risk premium associated with increased co-movement between inflation and consumption growth (columns 1, 2, and 3). This finding is robust to the inclusion of the average inflation and consumption growth (column 2). This association also is robust to the inclusion of the level of government debt, the inflation variance, and the consumption growth volatility as additional regressors (columns 3).

Furthermore, we regress the average change in debt on the conditional co-movement of inflation with consumption growth. As shown in Table 1, in countries/periods with higher conditional co-movement between inflation and consumption growth governments accumulate more debt (columns 4, 5, and 6). The estimation shows that it is important to control for the interest rates: this is consistent with the endogeneity of interest rates and debt accumulation. This finding on debt dynamics is also robust to the measure of government debt used (see appendix).

Overall, our results show that the co-movement of inflation and consumption growth not only affects interest rates but also debt dynamics. In the next section, we develop a theory to understand the relation between the inflation-consumption growth covariance, interest rates, and the dynamics of debt accumulation and default.

\section{Model}

\section{1 general thoughts}

Our main problem is that we can't get the full model (i.e. long term debt, low alpha ) to converge Alternatives: 1. Short term debt. Pro' it is simple, transparent, it is a full general eq. model of debt Cons. we can't get high enough equilibrium debt, but if we are willing to lower the target (only consider short term debt) and play with default cost, then maybe we can get a version which displays reasonable amounts of bedt with inferequent default The only other cost is that long term debt might be more affected by inflation, but we can deal with that in the appendix.

Alternative 2. Assume that the holders of debt have a SDF which is exogneous and equal to $u^{\prime}\left(y^{\prime}\right) / u^{\prime}(y)$ Pros, easy to compute, can discuss more issue related to maturities, can sustain large debt. One attractive feature of this solution is that it contains all the key 
Table 1: Inflation consumption growth co-movement, real interest rates, and debt dynamics

\begin{tabular}{|c|c|c|c|c|c|c|}
\hline & \multicolumn{3}{|c|}{ Real yield on government debt } & \multicolumn{3}{|c|}{ Change in government debt } \\
\hline & (1) & $(2)$ & (3) & $(4)$ & $(5)$ & $(6)$ \\
\hline Inflation consumption covariance & $\begin{array}{c}-2.518^{* * *} \\
(0.484)\end{array}$ & $\begin{array}{c}-2.636^{* * *} \\
(0.518)\end{array}$ & $\begin{array}{c}-2.357^{* * *} \\
(0.405)\end{array}$ & $\begin{array}{c}0.0270 \\
(0.0905)\end{array}$ & $\begin{array}{c}0.477^{* * *} \\
(0.136)\end{array}$ & $\begin{array}{c}0.494^{* * *} \\
(0.121)\end{array}$ \\
\hline Inflation & & $\begin{array}{l}0.0803 \\
(0.409)\end{array}$ & $\begin{array}{c}-0.0888 \\
(0.431)\end{array}$ & $\begin{array}{c}0.0132 \\
(0.0286)\end{array}$ & $\begin{array}{l}0.0254 \\
(0.155)\end{array}$ & $\begin{array}{c}0.00231 \\
(0.145)\end{array}$ \\
\hline Consumption growth & & $\begin{array}{c}-0.0175 \\
(0.726)\end{array}$ & $\begin{array}{l}-0.0421 \\
(0.704)\end{array}$ & $\begin{array}{c}-1.366^{* * *} \\
(0.209)\end{array}$ & $\begin{array}{c}-1.347^{* * *} \\
(0.219)\end{array}$ & $\begin{array}{c}-1.370^{* * *} \\
(0.262)\end{array}$ \\
\hline Lagged government debt & & $\begin{array}{c}-0.00623 \\
(0.00825)\end{array}$ & $\begin{array}{c}-0.00538 \\
(0.00905)\end{array}$ & $\begin{array}{c}-0.000278 \\
(0.00304)\end{array}$ & $\begin{array}{c}0.00197 \\
(0.00273)\end{array}$ & $\begin{array}{c}0.00193 \\
(0.00287)\end{array}$ \\
\hline Inflation variance & & & $\begin{array}{c}0.310 \\
(0.180)\end{array}$ & & & $\begin{array}{c}0.0456 \\
(0.0668)\end{array}$ \\
\hline Consumption variance & & & $\begin{array}{c}0.00766 \\
(0.185)\end{array}$ & & & $\begin{array}{l}-0.0214 \\
(0.0767)\end{array}$ \\
\hline Real yield on government debt & & & & & $\begin{array}{c}0.127^{* *} \\
(0.0465)\end{array}$ & $\begin{array}{l}0.124^{* *} \\
(0.0508)\end{array}$ \\
\hline $\operatorname{adj.} R^{2}$ & 0.769 & 0.782 & 0.787 & 0.492 & 0.571 & 0.572 \\
\hline$N$ & 2772 & 2682 & 2682 & 2870 & 2682 & 2682 \\
\hline
\end{tabular}

${ }^{*} p<0.10,{ }^{* *} p<0.05,{ }^{* * *} p<0.01$. Standard errors in parentheses. Standard errors clustered by country. All regressions include country and time fixed effects. The data is a quarterly unbalanced panel from 1960Q1 to 2012Q4 including AUS, AUT, BEL, CAN, CHE, DEU, DNK, ESP, FIN, FRA, GBR, GRC, ITA, JAP, KOR, MEX, NLD, NOR, POR, SWE, USA. All variables are computed over a forward-looking seven-year window. The co-movement of inflation and consumption growth is measured as the covariance of residuals within that window: $\operatorname{cov}_{t}\left(\varepsilon_{\pi i t}, \varepsilon_{g i t}\right)$. Other regressors are simple averages in the window. 
economics of our paper. We would lose only some technical complications. the draw back is that it is not structural.

Alternative 3 is to assume that the domestic representative agent is the debt holdsr and that default is not strategic, i.e. the government follows a fiscal rule

We extend the standard model of sovereign default of Eaton and Gersovitz (1981) and Arellano (2008) in two dimensions: exogenous inflation and risk averse domestic lenders.

\subsection{Households}

We consider a closed economy that is populated by a continuum of two types of households: poor, hand-to-mouth households who are impatient, and patient lenders. Both types of households have preferences given by

$$
E_{0} \sum_{t=0}^{\infty} \beta_{i}^{t} u\left(c_{i t}\right)
$$

where $0<\beta_{h}<\beta_{\ell}<1$ and $c_{h t}, c_{\ell t}$ are the discount factors and consumption at time $t$ of the hand-to-mouth households and lenders respectively. The households' period utility function is given by

$$
u(c)=\frac{c^{1-\gamma_{i}}}{1-\gamma_{i}}
$$

where $\gamma_{i}$ represents the risk aversion of household $i \in\{h, \ell\}$ The hand-to-mouth households receive a stochastic stream of non-storable consumption good $y$, which follows a Markov process. Lenders receive $\alpha y$ with $\alpha>1$.

\subsection{Government}

The government has access to debt markets in which it issues one-period non-contingent bonds to the domestic lenders. Bonds are risky because debt contracts are not enforceable which may lead to government default, and also because they may lose value due to exogenous inflation. Stochastic endowments $y$ and inflation $\pi$ follow a joint Markov Process. In the baseline model, we assume that the government maximizes the welfare of only the poor households, possibly due to political economy motives not explicitly modeled here. All 
proceeds from the government's debt operations are rebated to the poor households in a lump sum fashion. Let us denote: $(y, \pi) \equiv s$. Given the option to default, $V^{o}(B, s)$ satisfies

$$
V^{o}(B, s)=\max _{c, d}\left\{V^{c}(B, s), V^{d}(B, s)\right\}
$$

where $B$ is incoming government assets, $V^{c}$ is the value of not defaulting, and $V^{d}$ is the value of default.

When the government defaults, the economy is in financial autarky for a random number of periods and income may fall. Upon reentry after $k$ periods the government's debt obligation is $-\lambda^{k} B$. Setting $\lambda=0$ corresponds to the model with full default.

The government's value of default is then given by

$$
V^{d}(B, s)=u_{h}\left(y^{\text {def }}\right)+\beta_{h} \mathbf{E}_{s^{\prime} \mid s}\left[\theta V^{o}\left(\frac{\lambda B}{1+\pi^{\prime}}, s^{\prime}\right)+(1-\theta) V^{d}\left(\frac{\lambda B}{1+\pi^{\prime}}, s^{\prime}\right)\right]
$$

where $\theta$ is the probability that the government will regain access to credit markets, and

$$
y^{\operatorname{def}}= \begin{cases}\hat{y} & \text { if } y>\hat{y} \\ y & \text { if } y \leq \hat{y}\end{cases}
$$

The value of not defaulting, is given by

$$
V^{c}(B, s)=\max _{B^{\prime} \leq 0}\left\{u_{h}(c)+\beta_{h} \mathbf{E}_{s^{\prime} \mid s}\left[V^{o}\left(\frac{B^{\prime}}{1+\pi^{\prime}}, s^{\prime}\right)\right]\right\}
$$

where

$$
c=y+B-q\left(B, s, B^{\prime}\right) B^{\prime}
$$

and $q\left(B, s, B^{\prime}\right)$ is the bond price

\subsection{Lenders}

Let $\mu$ be the measure of lenders in the economy. Lenders take as given the policy functions for government assets, $B^{*}(B, s)$, and default, $d^{*}(B, s)$. If the government does not have 
access to credit markets, then the lender's value function is given by

$$
\begin{aligned}
W_{d}(b ; B, s)=\max _{b^{\prime}} & u_{\ell}\left(\alpha y^{\operatorname{def}}(y)-q^{\operatorname{def}}(B, s)\left(b^{\prime}-b\right)\right) \\
+\beta_{\ell} \mathbf{E}_{s^{\prime}} \mid s & \left\{\begin{array}{l}
\theta\left(1-d^{*}\left(\frac{\lambda B}{1+\pi^{\prime}}, s^{\prime}\right)\right) W_{c}\left(\frac{\lambda b^{\prime}}{1+\pi^{\prime}} ; \frac{\lambda B}{1+\pi^{\prime}}, s^{\prime}\right) \\
+\left(1-\theta+\theta d^{*}\left(\frac{\lambda B}{1+\pi^{\prime}}, s^{\prime}\right)\right) W_{d}\left(\frac{\lambda b^{\prime}}{1+\pi^{\prime}} ; \frac{\lambda B}{1+\pi^{\prime}}, s^{\prime}\right)
\end{array}\right\}
\end{aligned}
$$

where $q^{\text {def }}$ is the price of a bond in default (no trade in equilibrium), and $W_{c}$ is the lender's value function when the government has access to credit markets, which is given by

$$
\begin{aligned}
& W_{c}(b ; B, s)=\max _{b^{\prime}} \quad u_{\ell}\left(\alpha y+b-q^{*}(B, s) b^{\prime}\right) \\
&+\beta_{\ell} \mathbf{E}_{s^{\prime} \mid s}\left\{\begin{array}{l}
\left(1-d^{*}\left(\frac{\left.B^{*}(B, s)\right)}{1+\pi^{\prime}}, s^{\prime}\right)\right) W_{c}\left(\frac{b^{\prime}}{1+\pi^{\prime}} ; \frac{B^{*}(B, s)}{1+\pi^{\prime}}, s^{\prime}\right) \\
+d^{*}\left(\frac{B^{*}(B, s)}{1+\pi^{\prime}}, s^{\prime}\right) W_{d}\left(\frac{b^{\prime}}{1+\pi^{\prime}} ; \frac{B^{*}(B, s)}{1+\pi^{\prime}}, s^{\prime}\right)
\end{array}\right\}
\end{aligned}
$$

where $q^{*}(B, s)=q\left(B, s, B^{*}(B, s)\right)$

\subsection{Recursive equilibrium}

Definition The recursive equilibrium for this economy is defined as a set of policy functions for (i) lender assets $b^{*}(\cdot)$ and consumption $c_{\ell}^{*}(\cdot)$, (ii) government assets $B^{*}(\cdot)$ and default $d^{*}(\cdot)$, and (iii) a price function $q(\cdot)$ such that:

1. Taking as given government policies and bond price, the representative lender's policy functions solve the optimization problem in (7) and (8).

2. Taking as given the bond pricing function, the government's policy functions solve the optimization problem in (3), (4), and (6).

3. The bond market clears,

$$
\mu b^{*}+B^{*}=0 .
$$




\subsection{Characterization}

In this environment, the bond price satisfies

$$
\begin{aligned}
q\left(B, s, B^{\prime}\right)= & \beta_{\ell} \mathbf{E}_{s^{\prime} \mid s}\left[\frac{1-d^{*}\left(\frac{B^{\prime}}{1+\pi^{\prime}}, s^{\prime}\right)}{1+\pi^{\prime}} \frac{u_{\ell}^{\prime}\left(\alpha y^{\prime}-\frac{B^{\prime}}{1+\pi^{\prime}} \frac{1}{\mu}+q^{*}\left(\frac{B^{\prime}}{1+\pi^{\prime}}, s^{\prime}\right) \frac{B^{*}\left(\frac{B^{\prime}}{1+\pi^{\prime}}, s^{\prime}\right)}{\mu}\right)}{u_{\ell}^{\prime}\left(\alpha y-\frac{B}{\mu}+q\left(B, s, B^{\prime}\right) \frac{B^{\prime}}{\mu}\right)}\right] \\
& +\beta_{\ell} \mathbf{E}_{s^{\prime}} \mid s\left[\frac{d^{*}\left(\frac{B^{\prime}}{1+\pi^{\prime}} s^{\prime}\right)}{1+\pi^{\prime}} q^{\operatorname{def}}\left(\frac{B^{\prime}}{1+\pi^{\prime}}, s^{\prime}\right) \frac{u_{\ell}^{\prime}\left(\alpha y^{\operatorname{def}}\left(y^{\prime}\right)\right)}{u_{\ell}^{\prime}\left(\alpha y-\frac{B}{\mu}+q\left(B, s, B^{\prime}\right) \frac{B}{\mu}\right)}\right](10)
\end{aligned}
$$

where

$$
\begin{aligned}
& q^{\operatorname{def}}(B, s)=\beta_{\ell} \lambda \theta\left(1-d^{*}\left(\frac{\lambda B}{1+\pi^{\prime}}, s^{\prime}\right)\right) \\
& \mathbf{E}_{s^{\prime}} \mid s\left[\frac{1}{1+\pi^{\prime}} \frac{u_{\ell}^{\prime}\left(\alpha y^{\prime}-\frac{\lambda B}{1+\pi^{\prime}} \frac{1}{\mu}+q^{*}\left(\frac{\lambda B}{1+\pi^{\prime}}, s^{\prime}\right) B^{*}\left(\frac{\lambda B}{1+\pi^{\prime}}, s^{\prime}\right)\right)}{u_{\ell}^{\prime}\left(\alpha y^{d e f}(y)\right)}\right] \\
& +\beta_{\ell} \lambda\left(1-\theta+\theta d^{*}\left(\frac{\lambda B}{1+\pi^{\prime}}, s^{\prime}\right)\right) \mathbf{E}_{s^{\prime}} \mid s\left[\frac{q^{\text {def }}\left(\frac{\lambda B}{1+\pi^{\prime}}, s^{\prime}\right)}{1+\pi^{\prime}} \frac{u_{\ell}^{\prime}\left(\alpha y^{\text {def }}\left(y^{\prime}\right)\right)}{u_{\ell}^{\prime}\left(\alpha y^{d e f}(y)\right)}\right]
\end{aligned}
$$

The bond price can be rewritten as:

$$
\begin{aligned}
q\left(B, s, B^{\prime}\right)= & \beta_{\ell} \mathbf{E}_{s^{\prime}}\left|s\left[\frac{1-d^{*}\left(B^{\prime}, s^{\prime}\right)}{1+\pi^{\prime}}\right] \mathbf{E}_{s^{\prime}}\right| s\left[\frac{u^{\prime}\left(c_{\ell}^{*^{\prime}}\right)}{u^{\prime}\left(c_{\ell}^{*}\right)}\right] \\
& +\beta_{\ell} \operatorname{cov}_{s^{\prime}} \mid s\left[\frac{1-d^{*}\left(B^{\prime}, s^{\prime}\right)}{1+\pi^{\prime}}, \frac{u^{\prime}\left(c_{\ell}^{*^{\prime}}\right)}{u^{\prime}\left(c_{\ell}^{*}\right)} \mid s\right] \\
& +\beta_{\ell} \mathbf{E}_{s^{\prime}} \mid s\left[\frac{d^{*}\left(\frac{B^{\prime}}{1+\pi^{\prime}}, s^{\prime}\right)}{1+\pi^{\prime}} q^{\text {def }}\left(\frac{B^{\prime}}{1+\pi^{\prime}}, s^{\prime}\right) \frac{u_{\ell}^{\prime}\left(\alpha y^{\text {def }}\left(y^{\prime}\right)\right)}{\left.u_{\ell}^{\prime}\left(c_{\ell}^{*}\right)\right)}\right]
\end{aligned}
$$

The first term shows that the probability of default and inflation increase borrowing costs (standard effects). We focus on the co-movement of inflation and consumption growth: the 
second term shows that pro-cyclical inflation reduces borrowing costs (new channel). ${ }^{2}$ On the other hand, for the government, the covariance term means that the debt becomes more risky as the covariance of inflation and consumption growth increases.

\section{Quantitative analysis}

In this section, we use a calibrated version of the model to investigate the role of the inflation process on debt and default dynamics. First, in the model with no default, we assess the impact of different inflation processes on borrowing costs. Then, using the full model, we evaluate the impact of different inflation processes on borrowing costs, debt and default dynamics.

\subsection{Functional forms and parameters}

Endowments $y$ and inflation follows:

$$
\left[\begin{array}{c}
\log y^{\prime} \\
\pi^{\prime}
\end{array}\right]=\left[\begin{array}{cc}
\rho_{y} & \rho_{\pi, y} \\
\rho_{y, \pi} & \rho_{\pi}
\end{array}\right]\left[\begin{array}{c}
\log y \\
\pi
\end{array}\right]+\left[\begin{array}{c}
\epsilon_{y} \\
\epsilon_{\pi}
\end{array}\right]
$$

where

$$
\left[\begin{array}{c}
\epsilon_{y} \\
\epsilon_{\pi}
\end{array}\right] \sim N\left(\left[\begin{array}{l}
0 \\
0
\end{array}\right],\left[\begin{array}{cc}
\sigma_{y}^{2} & \sigma_{y \pi} \\
\sigma_{y \pi} & \sigma_{\pi}^{2}
\end{array}\right]\right)
$$

Since we consider a closed economy environment, output in our model is equal to consumption. This allows us to use our VAR results from (1) to guide our parameter values. Specifically, we set the persistence of output $\rho_{y}$ to 0.85 , the persistence of inflation $\rho_{\pi}$ to 0.85, the spillover terms $\rho_{y, \pi}$ and $\rho_{\pi, y}$ to zero, and the variance terms $\sigma_{y}$ and $\sigma_{\pi}$ to 0.01 and 0.015, which are in the range of estimates we obtain from the data. We consider two values for the covariance of inflation and output $\sigma_{\pi, y}$ : 0.000034 and -0.000034 . These represent a one standard deviation increase and decrease from the median of the covariance of inflation and consumption residuals computed at 7 year windows, which is close to zero.

\footnotetext{
${ }^{2}$ In addition, countercyclical default increases borrowing costs.
} 
We set the discount factor $\beta_{h}$ and risk aversion $\gamma_{h}$ of the government to match the average short-term debt in advanced economies, which is 20 percent of GDP, as documented by Abbas et al. (2014), and the elasticity of debt accumulation to the covariance of inflation and consumption, which we document to be 0.5 in panel (6) of Table 1 . We set the discount factor $\beta_{\ell}$ of the lender to be 0.99 to match an implied risk-free rate of 1 percent and the lender risk aversion $\gamma_{\ell}$ to be 2 , a standard value in the literature [we should calibrate this parameter as well: perhaps to match the average or volatility of the spread].

The probability of re-entry $\theta$ is set to match the average exclusion of 10 quarters as documented by Richmond and Dias (2008) and the recovery parameter $\lambda$ is set to be consistent with the average recovery rate of 50 percent reported by Benjamin and Wright (2009). To compute the average recovery rate, we take the following steps. First, we consider a default to be over when the government regains access to credit, which on average lasts 10 quarters. Second, we discount the payment back to period of default by an annualized interest rate of 10 percent as in Benjamin and Wright (2009).

Finally we set the asymmetric default penalty parameter to match a default frequency of 1 percent, and the relative income and size of the lenders to match the income ratio of the top 43 percent to the bottom 57 percent, which is 7 in the United States [source, what year?]. A summary of our parameters can be found in Table 2.

\subsection{Model with no default}

In the version of the model where we shut down the default margin, borrowing costs are significantly lower with procyclical inflation as shown in Table $3 .^{3}$

\subsection{Debt dynamics with default}

In the full model with default, we find that pro-cyclical inflation has two main effects on debt dynamics. The effects of the inflation co-movement are reported in Table 4. On the one hand, pro-cyclical inflation lowers equilibrium interest rates, inducing governments to go deeper into debt. On the other hand, this increases risk for the borrower, inducing government

\footnotetext{
${ }^{3}$ This difference in borrowing costs is also larger the higher the risk aversion.
} 
Table 2: Parameters

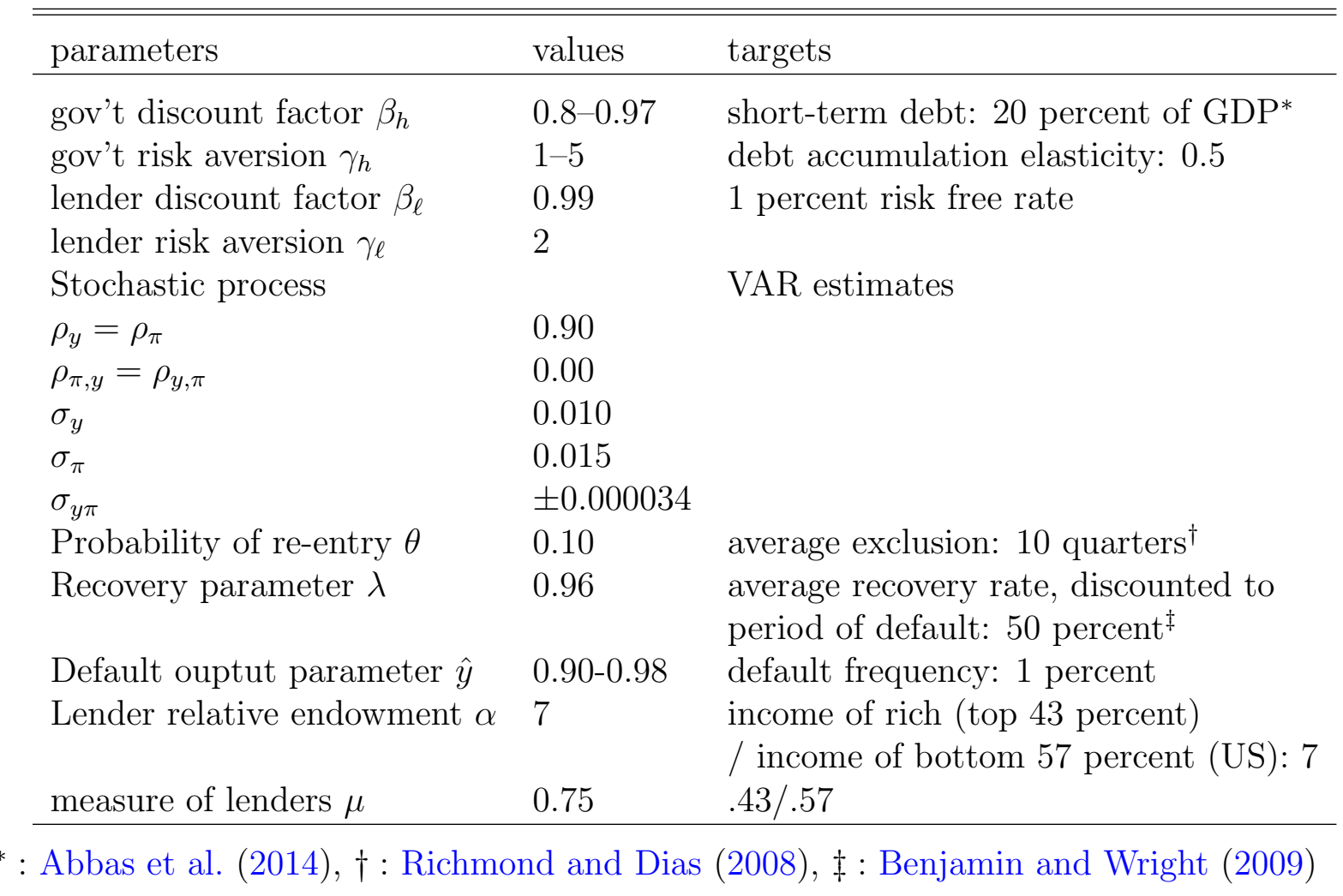

Table 3: Difference in Borrowing Costs (basis points)

\begin{tabular}{ll}
\hline \hline$\sigma$ & $r_{\text {cov- }}-r_{\text {cov }+}$ \\
\hline 2 & 12 \\
5 & 26 \\
\hline
\end{tabular}

to reduce debt. The first effect is stronger when the government has less debt, while the second effect is stronger when the government has more debt. Overall, default probabilities are lower when the inflation is more pro-cyclical - that is when the covariance of inflation and consumption growth increases. 
Table 4: Debt anddefault

Positive co-movement Negative co-movement

\begin{tabular}{lcc} 
& $\left(\sigma_{y \pi}=+0.00005\right)$ & $\left(\sigma_{y \pi}=-0.00005\right)$ \\
\hline \hline Default rate (percent) & 2.81 & 3.10 \\
Spreads (percent) & 2.82 & 3.63 \\
Debt (percent of borrower income) & 56.95 & 61.20 \\
\hline
\end{tabular}

\section{Precautionary motives}

Figure 4 shows that in response to the same sequence of shocks, precautionary motives from pro cyclical inflation increase with debt: the difference in debt accumulation between the two economies get larger as the debt levels increase. Figure 5 shows the evolution of borrowing costs for the same sequence of shocks. We find that borrowing costs are uniformly higher in the economy with countercyclical inflation.

Calibration and main quantitative results [TO BE COMPLETED]

\section{Conclusion}

The goal of this paper was to investigate how the inflation process affects borrowing costs, and debt and default dynamics. Empirically, we documented that the co-movement of inflation innovations and consumption growth innovations fluctuates over times across a large number of countries. Moreover, we find that increased co-movement of inflation and consumption growth is associated with lower borrowing costs. Theoretically, we showed that the inflation processes can be important in explaining the cross section of government debt and interest rates. 
Figure 4: Debt dynamics

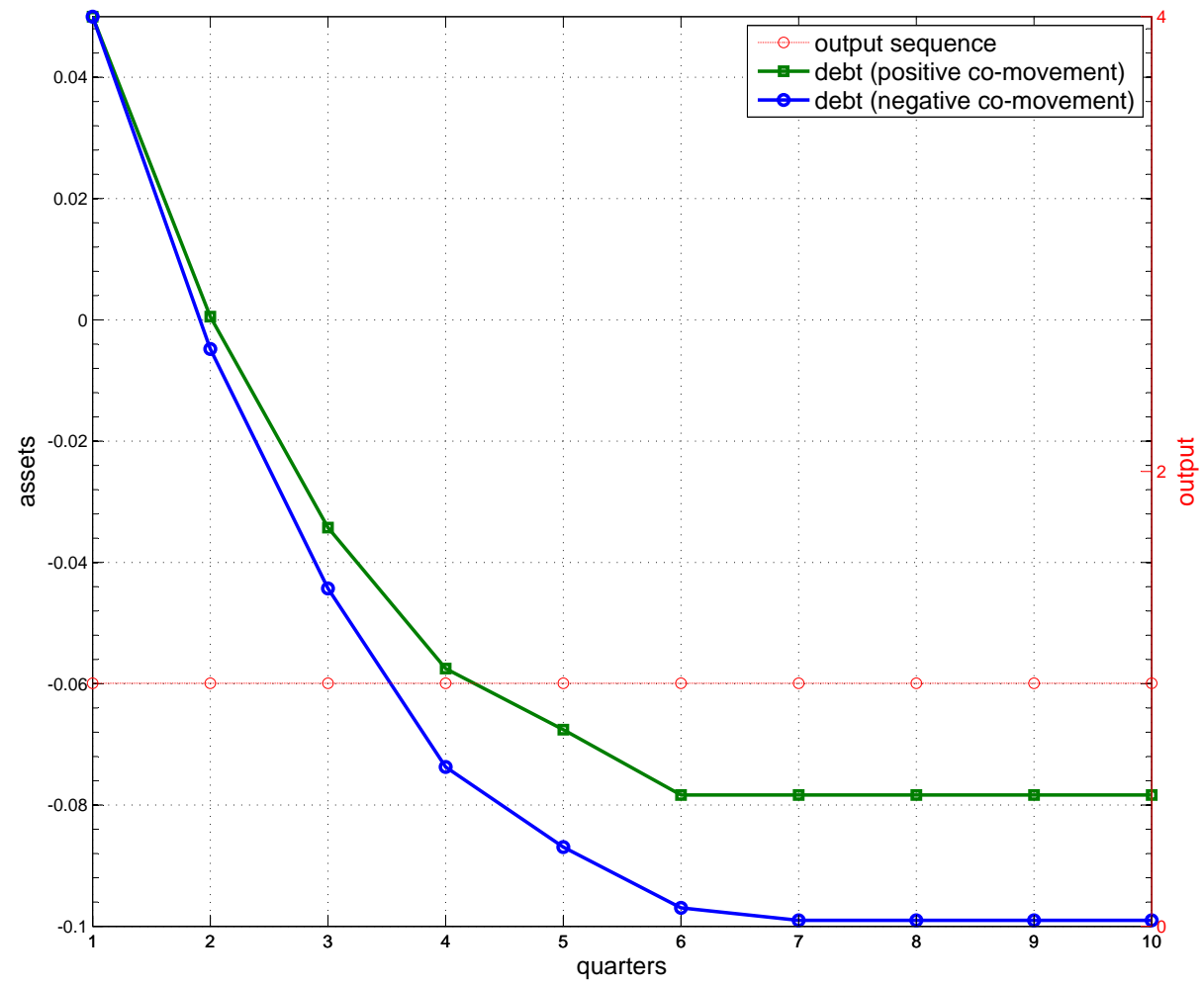


Figure 5: Interest rate

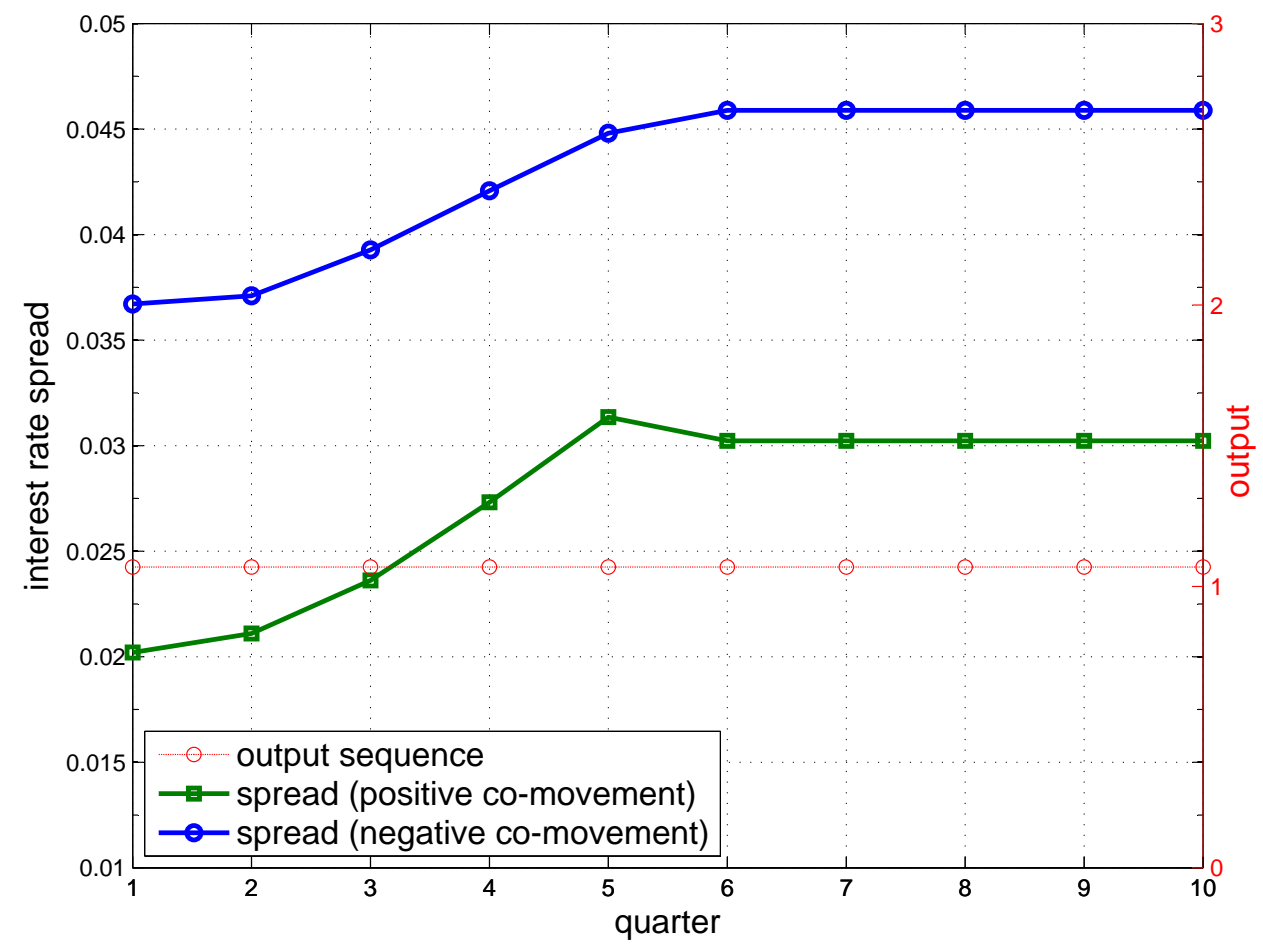




\section{References}

Abbas, SM Ali, Laura Blattner, Mark De Broeck, Ms Asmaa El-Ganainy, and Malin Hu, Sovereign debt composition in advanced economies: a historical perspective number 14-162, International Monetary Fund, 2014.

Aguiar, Mark and Gita Gopinath, "Defaultable debt, interest rates and the current account," Journal of international Economics, 2006, 69 (1), 64-83.

Aguiar, Mark, Manuel Amador, Emmanuel Farhi, and Gita Gopinath, "Crisis and commitment: Inflation credibility and the vulnerability to sovereign debt crises," Technical Report, National Bureau of Economic Research 2013.

Ang, Andrew, Geert Bekaert, and Min Wei, "The term structure of real rates and expected inflation," Journal of Finance, 2008, 63 (2), 797-849.

Arellano, Cristina, "Default risk and income fluctuations in emerging economies," American Economic Review, 2008, pp. 690-712.

Benjamin, David and Mark LJ Wright, "Recovery before redemption: A theory of delays in sovereign debt renegotiations," Available at SSRN 1392539, 2009.

Berriel, Tiago C and Saroj Bhattarai, "Hedging against the government: A solution to the home asset bias puzzle," American Economic Journal: Macroeconomics, 2013, 5 (1), $102-134$.

Boudoukh, Jacob, "An equilibrium model of nominal bond prices with inflation-output correlation and stochastic volatility," Journal of Money, Credit and Banking, 1993, pp. 636-665.

Broner, Fernando, Alberto Martin, and Jaume Ventura, "Sovereign risk and secondary markets," American Economic Review, 2010, pp. 1523-1555.

Brutti, Filippo and Philip U Sauré, "Transmission of sovereign risk in the euro crisis," Available at SSRN 2041257, 2012. 
Campbell, John Y, Adi Sunderam, and Luis M Viceira, "Inflation bets or deflation hedges? The changing risks of nominal bonds," Technical Report, National Bureau of Economic Research 2009.

Chatterjee, Satyajit and Burcu Eyigungor, "Maturity, Indebtedness, and Default Risk," American Economic Review, 2013, 102 (6), 2674-2699.

Corsetti, Giancarlo and Luca Dedola, "The Mystery of the Printing Press: Self-fulfilling debt crises and monetary sovereignty," 2013.

D'Erasmo, Pablo and Enrique Mendoza, "Domestic sovereign default as optimal redistributive policy," Unpublished Manuscript, University of Pennsylvania, 2012.

Eaton, Jonathan and Mark Gersovitz, "Debt with potential repudiation: Theoretical and empirical analysis," Review of Economic Studies, 1981, 48 (2), 289-309.

Fried, Daniel, "Inflation, Default and the Currency Composition of Sovereign Debt," in “2012 Meeting Papers" Midwest Macroeconomics Association 2012.

Hatchondo, Juan Carlos and Leonardo Martinez, "Long-duration bonds and sovereign defaults," Journal of International Economics, 2009, 79 (1), 117-125.

Lizarazo, Sandra Valentina, "Default risk and risk averse international investors," Journal of International Economics, 2013, 89 (2), 317-330.

Mendoza, Enrique G and Vivian Z Yue, "A general equilibrium model of sovereign default and business cycles," Technical Report, National Bureau of Economic Research 2011.

Neumeyer, Pablo Andres, "Currencies and the allocation of risk: The welfare effects of a monetary union," American Economic Review, 1998, pp. 246-259.

Pouzo, Demian and Ignacio Presno, "Optimal taxation with endogenous default under incomplete markets," Available at SSRN 2526646, 2014.

Reinhart, Carmen and Kenneth Rogoff, "The Forgotten History of Domestic Debt," Economic Journal, 2011, 121 (552), 319-350. 
Richmond, Christine and Daniel A Dias, "Duration of capital market exclusion: stylized facts and determining factors," Department of Economics, University of California, Los Angeles, 2008.

Song, Dongho, "Bond Market Exposures to Macroeconomic and Monetary Policy Risks," 2014.

\section{A Appendix}




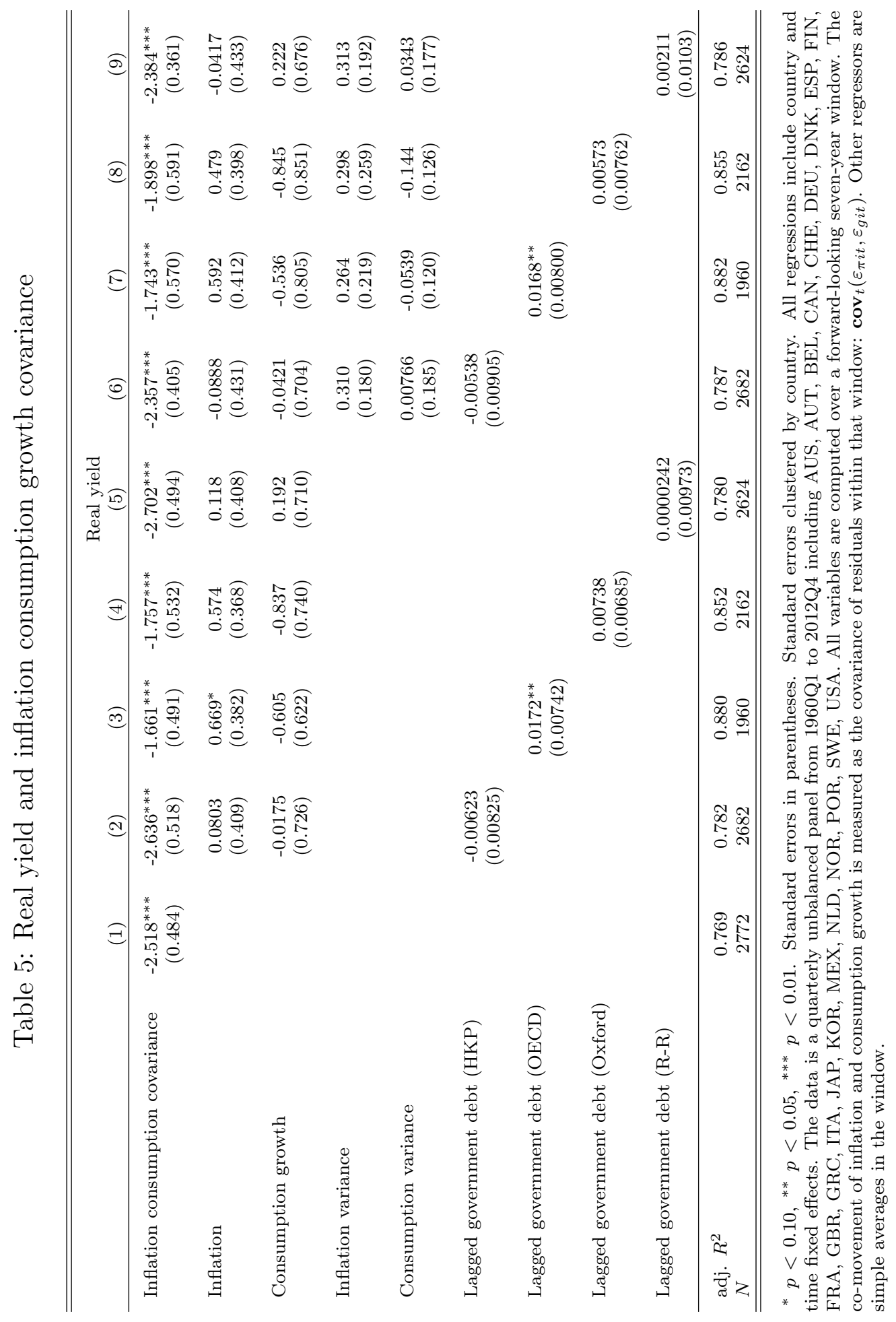




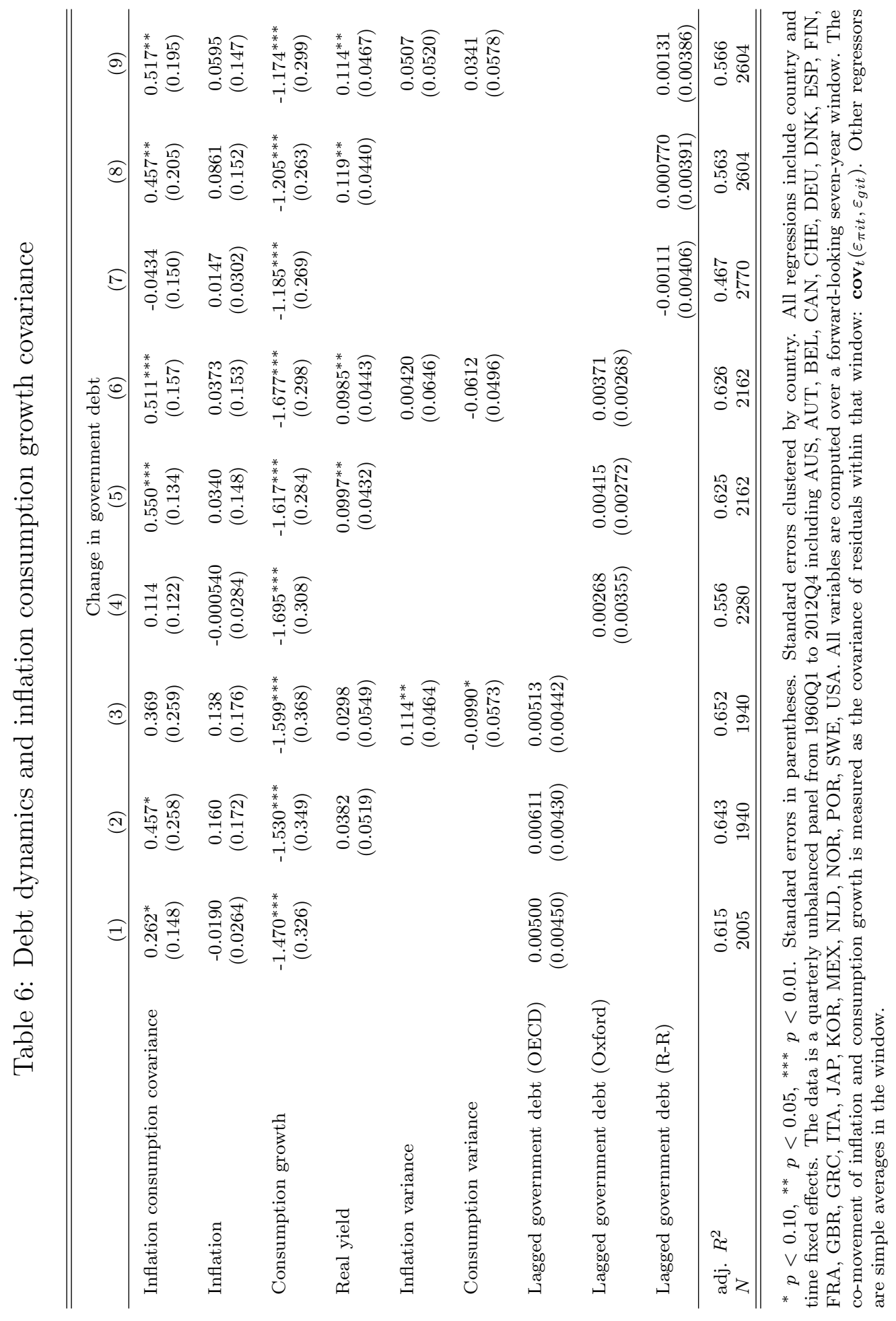




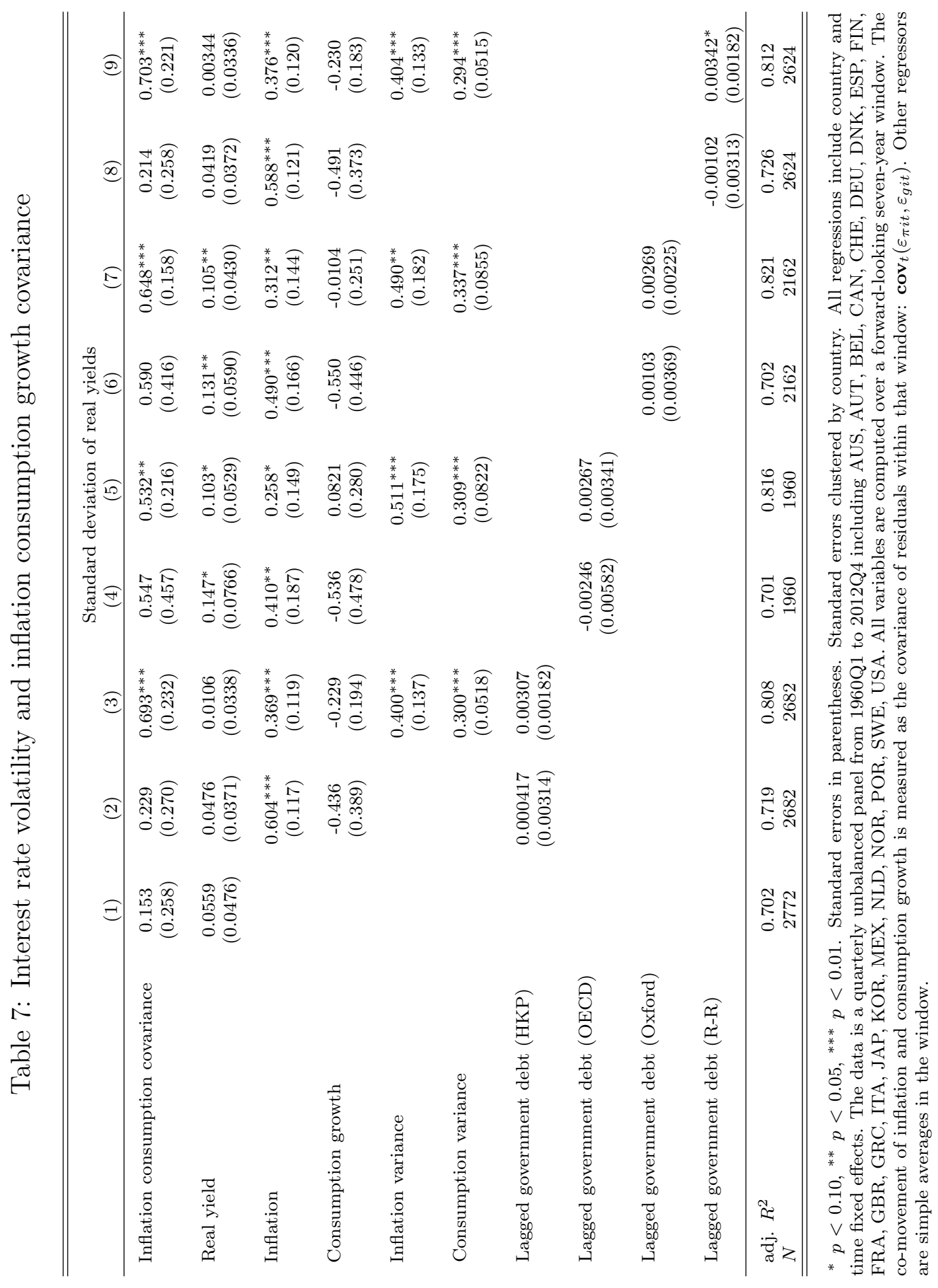

